\title{
Kinetic Investigation of Quaternary Ni-Fe-P-C Composite Coating as a New Catalyst for Hydrogen Evolution Reaction
}

\author{
Ali R. Madram ${ }^{a, *}$ Abolfazl F. Zonouz $^{b}$ and Hamid R. Pouretedal ${ }^{b}$ \\ ${ }^{a}$ Faculty of Chemistry and Chemical Engineering, Malek-Ashtar University of Technology, \\ Tehran 15875-1774, Iran \\ ${ }^{b}$ Department of Applied Chemistry, Malek-Ashtar University of Technology, \\ Isfahan 83145-115, Iran
}

Received 9 April 2015; accepted 15 June 2015

\begin{abstract}
A new quaternary $\mathrm{Ni}-\mathrm{Fe}-\mathrm{P}-\mathrm{C}$ composite coating was deposited on copper substrates by an electrodeposition process. The morphology, structure and composition of the prepared electrode were characterized using scanning electron microscopy (SEM), Xray diffraction (XRD) pattern, and energy dispersive X-ray spectroscopy (EDX). The activity of the composite coating toward hydrogen evolution reaction (HER) was evaluated on the basis of the steady-state polarization Tafel curves and electrochemical impedance spectroscopy (EIS) in $1 \mathrm{M} \mathrm{NaOH}$ at temperature of $298 \mathrm{~K}$. The experimental results revealed that the HER activity of the Ni-Fe-P-C coatings was enhanced compared with both ternary coatings of Ni-P-C and Ni-Fe-C. The source of its activity was found from its high surface area and its intrinsic properties. It was sufficient to assume the Volmer-Heyrovský mechanism with the Heyrovský reaction as the ratedetermining step to explain the experimental data. Besides the high electrocatalytic activity, excellent chemical and electrochemical stability were observed for Ni-Fe-P-C composite coating toward the HER in $1 \mathrm{M} \mathrm{NaOH}$ at $298 \mathrm{~K}$.
\end{abstract}

Keywords: hydrogen evolution reaction; quaternary $\mathrm{Ni}-\mathrm{Fe}-\mathrm{P}-\mathrm{C}$ coatings; composite coatings; electrochemical activity; electrocatalyst.

\section{Introduction}

Hydrogen is the cleanest and ideal fuel and it is considered as an ideal energy carrier that can be an alternative to fossil fuels [1]. Hydrogen evolution reaction (HER) is one of the most intensively studied reactions in electrochemistry because it occurs through a limited number of reaction steps with only one

\footnotetext{
* Corresponding author. E-mail address: Ar.madram@gmail.com
} 
reaction intermediate involved [2]. One major aspect of the research undertaken is to improve catalytic electrode materials in terms of their activity, efficiency and mechanical and corrosion stability [3]. Noble metals such as platinum and ruthenium are the most active materials, but these metals are very expensive [4]. Although non-platinum active metals such as $\mathrm{Fe}, \mathrm{Ni}$ or $\mathrm{Co}$ are considerably cheaper, they suffer from corrosion and passivation under the HER conditions and low electrocatalytic activity; therefore, great efforts are being made in order to improve electrocatalytic stability and activity of these materials, usually performed by alloying them and modifying their synthesis routes $[5,6]$. In recent years, many efforts have been made to develop new materials with high electrocatalytic activity and low-cost [7-10]. In the previous works [11,12] we reported the electrocatalytic activities of $\mathrm{Ni}-\mathrm{Fe}-\mathrm{C}$ and $\mathrm{Ni}-\mathrm{P}-\mathrm{C}$ composite electrodes toward the HER, where the activities were improved mainly by increasing the intrinsic activity induced by carbon embedded to $\mathrm{Ni}-\mathrm{Fe}$ and $\mathrm{Ni}-\mathrm{P}$ matrix, respectively. The current study was planned to combine interesting properties of Ni-P-C composite (i.e., excellent physical stability and moderate electrocatalytic activity) with those of iron in $\mathrm{Ni}-\mathrm{Fe}-\mathrm{C}$ composite (i.e., excellent activity) to fabricate a new type of catalyst (Ni-Fe-P-C) and examine its activity for the HER in alkaline solution by steady-state polarization Tafel curves, and electrochemical impedance spectroscopy (EIS).

Table 1. Composition and operating conditions of the plating baths (see the text for details).

\begin{tabular}{|c|c|c|c|}
\hline $\begin{array}{l}\text { Constituents and operating } \\
\text { conditions of plating baths }\end{array}$ & A & B & C \\
\hline $\mathrm{NiSO}_{4} \cdot 7 \mathrm{H}_{2} \mathrm{O}(\mathrm{M})$ & 1.14 & 1.14 & 1.14 \\
\hline $\mathrm{NiCl}_{2} \cdot 6 \mathrm{H}_{2} \mathrm{O}(\mathrm{M})$ & 0.19 & 0.19 & 0.19 \\
\hline $\mathrm{H}_{3} \mathrm{BO}_{3}(\mathrm{M})$ & 0.49 & 0.49 & 0.49 \\
\hline $\mathrm{Na}_{3} \mathrm{C}_{6} \mathrm{H}_{5} \mathrm{O}_{7} \cdot 2 \mathrm{H}_{2} \mathrm{O}(\mathrm{M})$ & 0.12 & --- & 0.12 \\
\hline $\mathrm{NaH}_{2} \mathrm{PO}_{2} \cdot \mathrm{H}_{2} \mathrm{O}(\mathrm{M})$ & --- & 0.14 & 0.14 \\
\hline $\mathrm{FeSO}_{4} \cdot 7 \mathrm{H}_{2} \mathrm{O}(\mathrm{M})$ & --- & --- & 0.10 \\
\hline L-lysine $(\mathrm{M})$ & --- & --- & 0.06 \\
\hline Applied current $\left(\mathrm{mA} \mathrm{cm}^{-2}\right)$ & 22 & 22 & 13 \\
\hline Temperature $(\mathrm{K})$ & 298 & 298 & 298 \\
\hline
\end{tabular}

\section{Experimental}

\section{Electrode preparation}

All chemicals were of analytical reagent grade and were used as received and also the all solutions were prepared by double distilled water. Electrodeposition of the quaternary Ni-Fe-P-C composite coatings was carried out under constant current in a double wall glass cell containing a volume of $300 \mathrm{~mL}$ of depositing electrolyte, a copper rod sealed in a heat shrinkable tube exposing a $0.229 \mathrm{~cm}^{2}$ surface area as substrate, and a platinum plate (purity of $99.99 \%$ and surface area $>25 \mathrm{~cm}^{2}$ ) as counter electrode. Before electrodeposition, the copper substrate was polished with sandpaper (P 600, Siawats), washed with water, immersed in a 1:1 $\mathrm{HNO}_{3}$ solution, washed with water, and immediately introduced into the cell for electrodeposition. The simple electrodeposition method of Ni-Fe-P-C was performed in a three-step method. Composition of the bath and electrodeposition conditions of each step are given in Table 1. (i) First, a layer of Ni was deposited 
from bath $\mathrm{A}$, (ii) then $\mathrm{Ni}-\mathrm{P}$ was coated on $\mathrm{Ni}$ from bath $\mathrm{B}$ and finally (iii) $\mathrm{Ni}-\mathrm{Fe}-\mathrm{P}-\mathrm{C}$ deposited from bath $\mathrm{D}$. The electrodeposition steps were performed in $30 \mathrm{~min}$ for each bath and at temperature of $298 \mathrm{~K}$.

\section{Electrochemical measurements}

A two-compartment Pyrex ${ }^{\circledR}$ glass cell, consisting of a large surface area Pt plate electrode as the counter electrode and an external $\mathrm{Hg} / \mathrm{HgO} / 1 \mathrm{M} \mathrm{NaOH}$ electrode as the reference electrode was used for electrochemical measurements. The details of the electrochemical cell have been described previously [11]. All measurements were performed in purified $1 \mathrm{M} \mathrm{NaOH}$ degassed with argon (99.99\%). The steady-state polarization Tafel curves and EIS measurements were carried out using a Parstat 2273 Potentiostat/Galvanostat. The details of the measurements have been described previously [11]. The Tafel plots were recorded galvanostatically (45 s after a constant current application) at cathodic current densities range from $\mathrm{j}=-100 \mathrm{~mA} \mathrm{~cm}^{-2}$ to $\mathrm{j}=-1 \mu \mathrm{A} \mathrm{cm} \mathrm{cm}^{-2}$. At the steady state, the electrode potentials were recorded for iR drop, determined by the EIS method at various electrode potentials. The EIS measurements were performed at the steady-state [11,12]. Surface morphology and chemical composition of the alloys were investigated by scanning electron microscopy (SEM) and energy dispersive X-ray diffraction microanalysis (EDX) (Philips-XL-30). Crystal structure of the alloys was determined by X-ray diffraction (XRD) analysis (Philips-X'Pert-MPD) using $\mathrm{Cu} \mathrm{K}_{\alpha}$ wavelength of $1.5418 \AA$.

\section{Results and discussion}

\section{Composition and surface morphology of the coatings}

The SEM micrograph and a typical EDX spectrum obtained on the surface of the as-deposited Ni-Fe-P-C coating surface are shown in Figs. 1 and 2, respectively. The SEM micrographs of the investigated quaternary coating (Fig. 1) displayed globular island-structure. This structure is probably accountable for high electrochemical activity and large real surface area of the quaternary Ni-Fe-P-C coating. Furthermore, the quaternary coating of Ni-Fe-P-C showed good adherence to the lower layers (Ni-P layer deposited from bath B in Table 1) and good physical stability and was hard and difficult to remove with a sandpaper. The experiment was not successful if the second layer in the coating (bath B in Table 1) was changed with Ni-Fe. The EDX spectrum shows that the chemical composition of the top layer of the coatings prepared under optimized conditions (Table 1) was $\mathrm{Ni}_{61} \mathrm{Fe}_{19} \mathrm{P}_{17} \mathrm{C}_{3}$. The diffraction pattern (Fig. 3) of the $\mathrm{Ni}-\mathrm{Fe}-\mathrm{P}-\mathrm{C}$ coating shows an amorphous structure with a main broad peak centered at 44.5 $\AA$. 


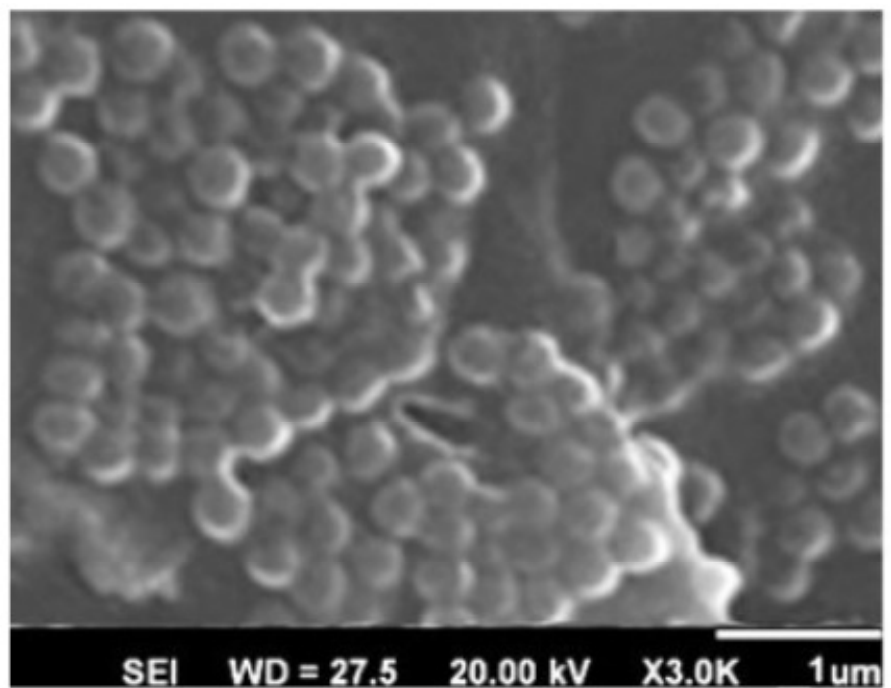

Figure 1. The SEM image of as-deposited Ni-Fe-P-C composite coating.

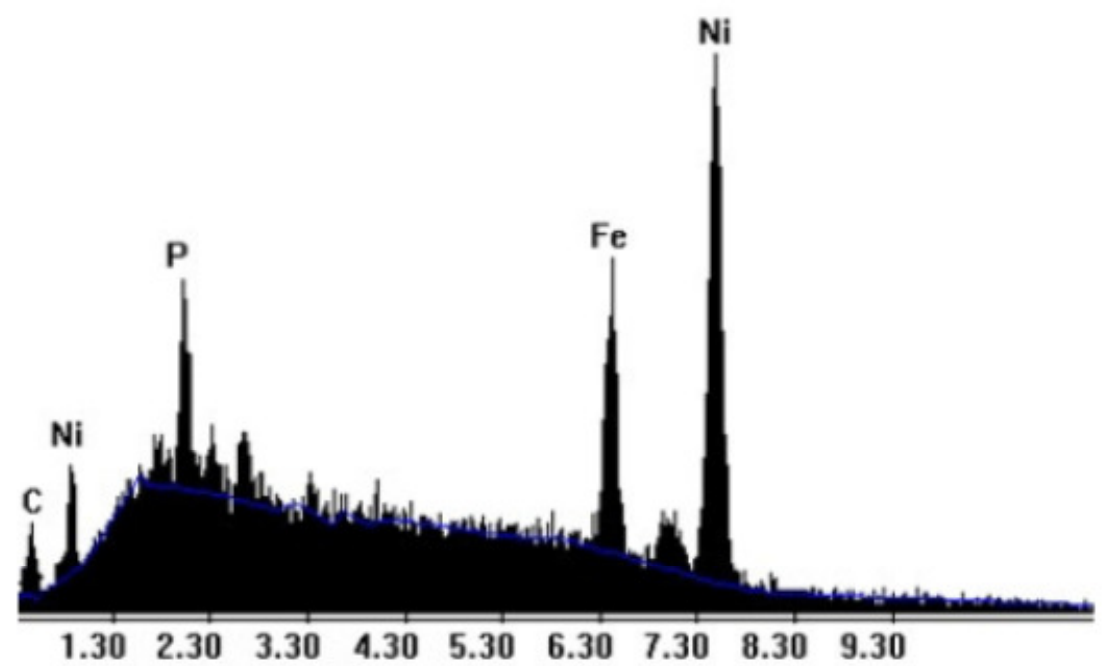

Figure 2. Energy dispersive X-ray diffraction (EDX) microanalysis spectrum of asdeposited $\mathrm{Ni}_{61} \mathrm{Fe}_{19} \mathrm{P}_{17} \mathrm{C}_{3}$ electrode.

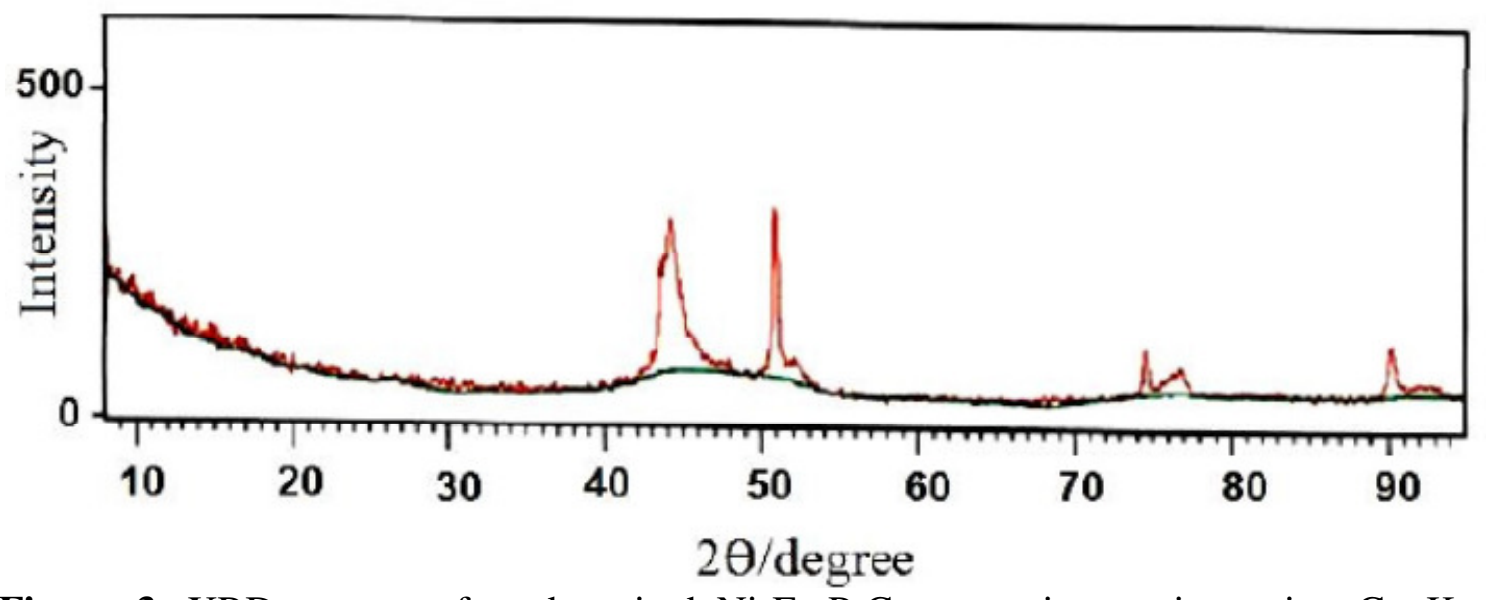

Figure 3. XRD spectra of as-deposited Ni-Fe-P-C composite coating using $\mathrm{Cu} \mathrm{Ka}$ wavelength of $1.5418 \AA$. 


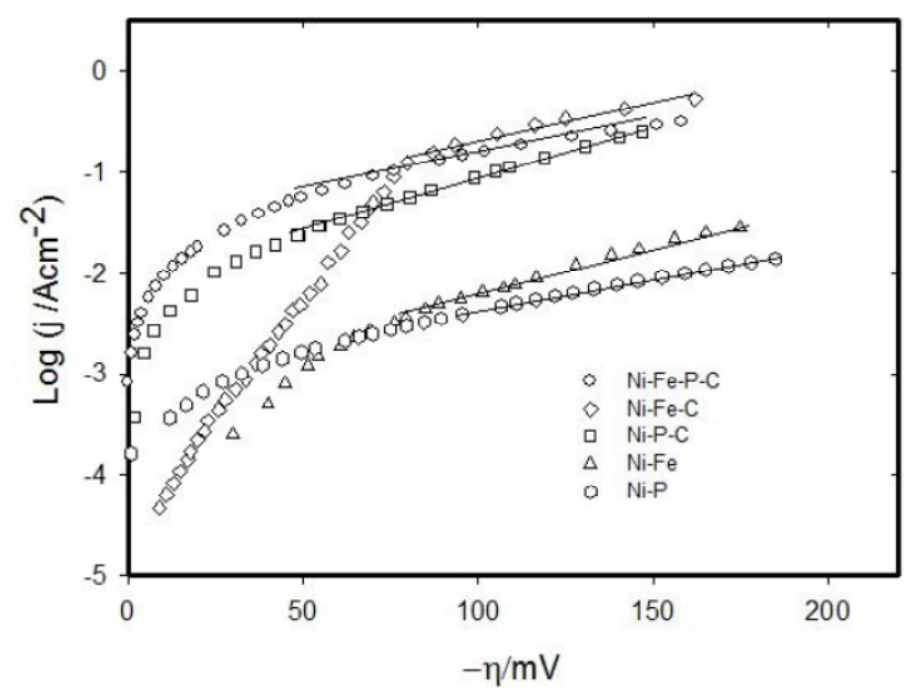

Figure 4. Steady-state polarization Tafel curves obtained on Ni-P, Ni-Fe, Ni-P-C, Ni$\mathrm{Fe}-\mathrm{C}$ and $\mathrm{Ni}-\mathrm{Fe}-\mathrm{P}-\mathrm{C}$ coatings in $1 \mathrm{M} \mathrm{NaOH}$ at $298 \mathrm{~K}$ on the investigated electrodes.

\section{Kinetic studies}

\section{Steady-state polarization curves}

The apparent activity of the electrode was studied by steady-state polarization Tafel curves for the HER in $1 \mathrm{M} \mathrm{NaOH}$ on Ni-Fe-P-C composite coating at 298 $\mathrm{K}$ in argon atmosphere. The iR-corrected Tafel curves for $\mathrm{Ni}-\mathrm{Fe}$ and $\mathrm{Ni}-\mathrm{Fe}-\mathrm{C}$, $\mathrm{Ni}-\mathrm{P}$ and Ni-P-C, and Ni-Fe-P-C are displayed in Fig. 4 and the kinetic parameters of the HER determined from linear part of the Tafel curves, i.e. exchange current density $\left(\mathrm{j}_{0}\right)$, Tafel slopes $(b)$, and overpotential at $\mathrm{j}=250 \mathrm{~mA}$ $\mathrm{cm}^{-2}\left(\eta_{250}\right)$ are presented in Table 2 . These parameters were calculated taking into account the geometric surface area of the investigated coatings. The Tafel curves for the quaternary coating showed only one Tafel slope in the whole range of the studied potentials (Fig. 4), that is similar to Ni-P based coatings. In terms of $\mathrm{j}_{0}$, Table 2 shows that Ni-Fe-P-C coating was more active catalyst toward the HER than other ternary coatings at the HER equilibrium potential. The value of $\mathrm{j}_{0}$ for the Ni-Fe-P-C $\left(32.4 \times 10^{3} / \mathrm{A} \mathrm{cm}^{-2}\right)$ was higher than the Ni-P-C $\left(12.2 \times 10^{3}\right.$ $\left./ \mathrm{A} \mathrm{cm}^{2}\right)$ and Ni-Fe-C $\left(24.5 \times 10^{3} / \mathrm{A} \mathrm{cm}^{-2}\right)$ coatings. Furthermore, at far from equilibrium, i.e., high current densities, a comparison of $\eta_{250}$ values for the quaternary Ni-Fe-P-C coating $\left(-\eta_{250}=136.0 \mathrm{mV}\right)$ with the ternary coatings of Ni-P-C $\left(-\eta_{250=} 146.0 \mathrm{mV}\right)$ and Ni-Fe-C $\left(-\eta_{250=} 112.6 \mathrm{mV}\right)$ indicates that the quaternary coating had higher activity than Ni-P-C, but lower activity than $\mathrm{Ni}-\mathrm{Fe}-\mathrm{C}$ coating toward the HER. Although, it was predictable from previous work [11] that the higher content of iron in the composite coatings could enhance its intrinsic activity toward the HER, we observed a decrease in stability of the quaternary coatings if the iron value was larger than the values showed in Table 1 (bath B). However, the steady-state polarization studies, alone, are not enough to explain the kinetics of HER. Thus, more precise information was obtained by the EIS, and analyzed in conjunction with Tafel curve data to find the source of increased activities. 
Table 2. Kinetic parameters for the HER obtained on as deposited Ni-P, Ni-Fe, Ni-P-C, $\mathrm{Ni}-\mathrm{Fe}-\mathrm{C}$ and $\mathrm{Ni}-\mathrm{Fe}-\mathrm{P}-\mathrm{C}$ coatings in $1 \mathrm{M} \mathrm{NaOH}$ solution at $298 \mathrm{~K}$ by using steady state polarization Tafel curves.

\begin{tabular}{|c|c|c|c|}
\hline Coatings & $\left.\mathbf{j}_{0} \times 10^{3} / \mathrm{A} \mathrm{cm}^{-2}\right)^{a}$ & $\left.\mathrm{~b} / \mathrm{mV} \operatorname{dec}^{-1}\right)^{b}$ & $\left.-\eta_{250} / \mathrm{mV}\right)^{c}$ \\
\hline $\mathrm{Ni}-\mathrm{P}$ & 3.2 & 117.0 & 225.0 \\
\hline $\mathrm{Ni}-\mathrm{Fe}$ & 2.1 & 120.7 & 251.2 \\
\hline Ni-P-C & 12.2 & 125.0 & 146.0 \\
\hline $\mathrm{Ni}-\mathrm{Fe}-\mathrm{C}$ & 24.5 & 111.6 & 112.6 \\
\hline $\mathrm{Ni}-\mathrm{Fe}-\mathrm{P}-\mathrm{C}$ & 32.4 & 121.0 & 136.0 \\
\hline
\end{tabular}

\section{Electrochemical impedance spectroscopy (EIS)}

In the present work, the EIS measurements were used to investigate the interfacial behavior and activities of the $\mathrm{Ni}-\mathrm{Fe}-\mathrm{P}-\mathrm{C}$ composite electrode toward the HER in a wide range of frequency and potential. The values of electrode potentials at which the EIS measurements are taken were chosen from the linear part of the potential region obtained by d.c. polarization measurements. A typical impedance diagram for the quaternary $\mathrm{Ni}-\mathrm{Fe}-\mathrm{P}-\mathrm{C}$ coating at various overpotentials in $1 \mathrm{M} \mathrm{NaOH}$ is presented in Fig. 5. It can see that the Niquist diagram (Fig. 5 A) looks like only one slightly distorted capacitive semicircle in the entire range of the studied overpotentials. After testing the models related to the HER [13,14], considering the fit criteria such as "number of model parameters" and "Chi square values" [15], the CPE model was found to be enough for approximations of the EIS data of the investigating electrode. Approximation of the experimental EIS data with one-CPE model permitted estimation of the solution resistance $\left(R_{s}\right)$, capacitive parameter $(T)$ related to the average double layer capacitance $\left(C_{d l}\right)$, charge transfer resistance $\left(R_{c t}\right)$ and dispersion parameter related to the CPE model $(\varphi)$. Additionally, determination of the exact number of active sites per unit of surface area is a difficult task [16]; however, a comparison between values of $20 \mu \mathrm{Fcm}^{-2}$ assumed for the double layer capacitance of a smooth electrode [17] and the $\mathrm{C}_{\mathrm{dl}}$ of objective electrode is a suitable method to estimate surface roughness $\left(\mathrm{R}_{\mathrm{f}}\right)$ :

$$
\mathrm{R}_{\mathrm{f}}=\overline{\mathrm{C}}_{\mathrm{dl}} / 20 \mu \mathrm{Fcm}^{-2}
$$

The value of 4908 was obtained for $\mathrm{R}_{\mathrm{f}}$ of the Ni-Fe-P-C by approximation of the EIS data (Table 3, column 4). This high real surface area confirmed the SEM micrograph of the investigated coating (Fig. 1) and is one of the high activity sources of Ni-Fe-P-C toward the HER. The increasing factor of the $\mathrm{R}_{\mathrm{f}}$ from the quaternary Ni-Fe-P-C coating to Ni-P-C and Ni-Fe-C was $78 \%$ and $16 \%$, respectively. Also, the decreasing factor of the $\mathrm{R}_{\mathrm{ct}}$ from Ni-Fe-P-C to Ni-P-C and $\mathrm{Ni}-\mathrm{Fe}-\mathrm{C}$ was $94 \%$ and $55 \%$, respectively. Therefore, the EIS studies revealed that $\mathrm{Ni}-\mathrm{Fe}-\mathrm{P}-\mathrm{C}$ coating was more active catalyst for the HER than ternary coatings of $\mathrm{Ni}-\mathrm{P}-\mathrm{C}$ and $\mathrm{Ni}-\mathrm{Fe}-\mathrm{C}$ that were reported previously $[11,12]$. 

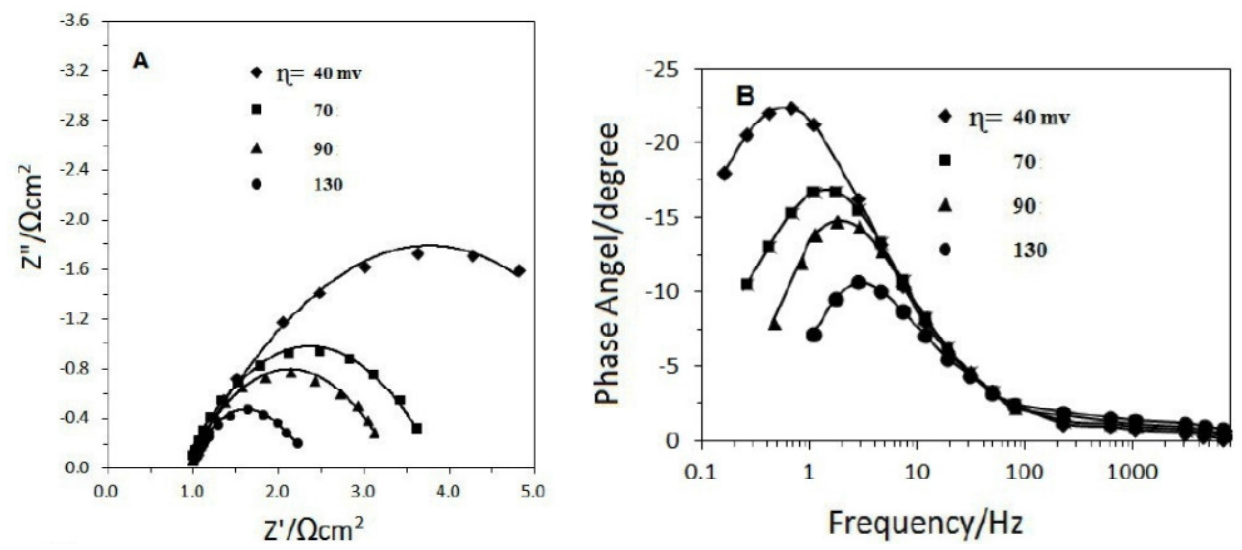

Figure 5. Complex plane (A) and Bode (B) plots of the EIS measurements obtained for the HER on Ni-Fe-P-C composite coating at various overpotentials in $1 \mathrm{M} \mathrm{NaOH}$ at 298 K. Continuous lines show the approximated data using linear regression analysis, and symbols represent the experimental data.

Table 3. Some information resulted by EIS measurements on Ni-P, Ni-Fe, Ni-P-C, Ni$\mathrm{Fe}-\mathrm{C}$ and $\mathrm{Ni}-\mathrm{Fe}-\mathrm{P}-\mathrm{C}$ coatings for the HER in $1 \mathrm{M} \mathrm{NaOH}$ at $298 \mathrm{~K}$.

\begin{tabular}{lccc}
\hline Coating & $\mathbf{C}_{\mathrm{dllave}}{ }^{\mathbf{a}}\left(\boldsymbol{\mu} \mathbf{F} \mathbf{c m}^{-2}\right)$ & $\mathbf{R}_{\mathbf{f}}{ }^{\mathbf{b}}$ & $\mathbf{R}_{\mathbf{c t}} / \mathbf{\Omega} \mathbf{~ c m}^{\mathbf{2}}$ \\
\hline Ni-P & 1160 & 1930 & 103.5 \\
Ni-Fe & 59000 & 2950 & 18.5 \\
Ni-P-C & 4790 & 2760 & 23.1 \\
Ni-Fe-C & 85000 & 4250 & 2.9 \\
Ni-Fe-P-C & 98156 & 4908 & 1.3 \\
\hline
\end{tabular}

${ }^{a}$ Average double layer capacitance; ${ }^{b}$ Roughness factor assuming a double layer capacitance of $20 \mu \mathrm{Fcm}^{-2}$ for smooth polycrystalline nickel electrode; ${ }^{\mathrm{c}}$ Charge transfer resistance at $\eta=-130 \mathrm{mV}$

\section{Rate constants}

The determination of the HER rate constants for the studied materials is very import, because it helps us to find some valuable kinetic information such as: HER mechanism and rate determining step, intrinsic activity (synergetic effect) of new catalysts for the HER and precise determination of the HER activity sources. Different methods as galvanostatic step, open circuit potential decay, and Tafel-impedance have been already reported to be effective for evaluation of the rate constants of the HER in alkaline solutions [18]. The kinetic parameters for the quaternary coating were extracted by simultaneous fitting of the Tafel and EIS data (i.e., Tafel-impedance method) to corresponding kinetic equations using the NLS method [19]. The details of the method for determining the HER rate constant have been described previously [11]. The mechanism of HER in alkaline solution involves the formation of an adsorbed hydrogen atom intermediate, $\mathrm{MH}_{\mathrm{ads}}$ (Volmer reaction):

$$
\mathrm{H}_{2}+\mathrm{M}+\mathrm{e}^{-} \rightarrow \mathrm{MH}_{\mathrm{ads}}+\mathrm{OH}^{-}
$$

the electrochemical desorption of hydrogen into solution (Heyrovský reaction):

$$
\mathrm{H}_{2} \mathrm{O}+\mathrm{MH}_{\mathrm{ads}}+\mathrm{e}^{-} \rightarrow \mathrm{H}_{2}+\mathrm{M}+\mathrm{OH}^{-}
$$

and/or a chemical desorption by the combination of two atoms (Tafel reaction): 


$$
\mathrm{MH}_{\mathrm{ads}}+\mathrm{MH}_{\mathrm{ads}} \rightarrow \mathrm{H}_{2}+2 \mathrm{M}
$$

where $\mathrm{M}$ represents the electrode materials and $\mathrm{MH}_{\mathrm{ads}}$ the hydrogen adsorbed on coating surface.

A linear variation was observed for $\log \left(1 / \mathrm{R}_{\mathrm{ct}}\right)$ as a function of $\eta$ for the $\mathrm{Ni}-\mathrm{Fe}-$ P-C electrode (Fig. 6). The obtained value $128 \mathrm{mVdec}^{-1}$, for slope of $\mathrm{Ni}-\mathrm{Fe}-\mathrm{P}-\mathrm{C}$ coating at $298 \mathrm{~K}$ was in good agreement with those obtained from Tafel curve (Fig. 4 and Table 2) and predicts the Volmer-Heyrovsk'y reaction mechanism [19] for the HER on the investigated quaternary coating.

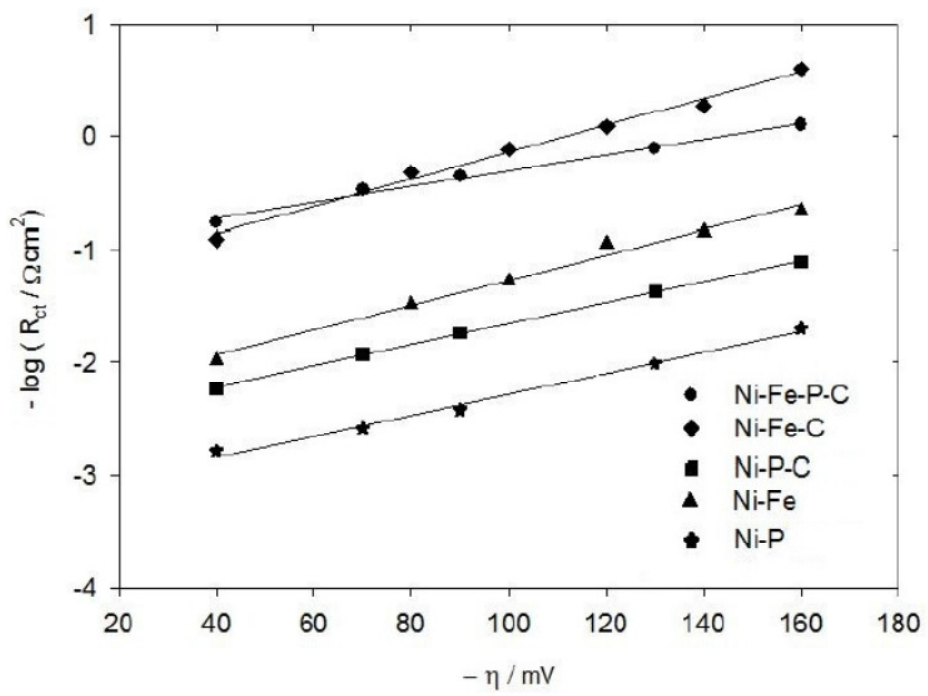

Figure 6. Dependence of the inverse of the charge transfer resistance $\left(1 / \mathrm{R}_{\mathrm{ct}}\right)$ on the overpotential obtained for the HER in $1 \mathrm{M} \mathrm{NaOH}$ on Ni-P, Ni-Fe, Ni-P-C, Ni-Fe-C and $\mathrm{Ni}-\mathrm{Fe}-\mathrm{P}-\mathrm{C}$ composite coatings. Symbols indicate experimental results and solid lines approximated data.

The determined rate constant (Heyrovský reaction) value $\mathrm{k}_{2}$ was smaller than $\mathrm{k}_{1}$ rate constant (Volmer reaction) for the Ni-Fe-P-C coating, and hence the Heyrovský reaction was detected as the rate-determining step. Similar results were previously observed for the ternary coatings of Ni-P-C and $\mathrm{Ni}-\mathrm{Fe}-\mathrm{C}$, $[11,12]$. The values of $k_{1}, k_{2}$, average apparent rate constants $\left(k_{a v}=\left(k_{1}{ }^{-1}+k_{2}^{-1}\right)^{-1}\right)$, intrinsic activity $\left(\mathrm{k}_{\mathrm{intr}}=\mathrm{k}_{\mathrm{av}} / \mathrm{R}_{\mathrm{f}}\right)$, real exchange current densities $\left(\mathrm{j}_{0} / \mathrm{R}_{\mathrm{f}}\right)$ and symmetry factors $\left(\beta_{1}\right.$ and $\beta_{2}$ ) [4] for quaternary and ternary coatings are presented in Table 4 . The value of $\mathrm{k}_{\mathrm{av}}$ for the quaternary Ni-Fe-P-C coating $\left((1.4 \pm 0.3) \times 10^{-7} \mathrm{~mol} \mathrm{~cm}^{-2} \mathrm{~s}^{-1}\right)$ is almost two orders of magnitude larger than those for both ternary Ni-P-C $\left((5.2 \pm 0.3) \times 10^{-9} \mathrm{~mol} \mathrm{~cm}^{-2} \mathrm{~s}^{-1}\right)$ and Ni-Fe-C $\left((4.5 \pm 0.5) \times 10^{-9} \mathrm{~mol} \mathrm{~cm}^{-2} \mathrm{~s}^{-1}\right)$ coatings. Furthermore, higher intrinsic activity was also observed on the quaternary Ni-Fe-P-C $\left((2.9 \pm 0.3) \times 10^{-11} \mathrm{~mol} \mathrm{~cm}^{-2} \mathrm{~s}^{-1}\right)$ as compared with ternary Ni-Fe-C $\left((1.1 \pm 0.5) \times 10^{-12} \mathrm{~mol} \mathrm{~cm}^{-2} \mathrm{~s}^{-1}\right)$ and somewhat Ni-P-C $\left((2.2 \pm 0.3) \times 10^{-11} \mathrm{~mol} \mathrm{~cm}^{-2} \mathrm{~s}^{-1}\right)$ coatings. Additionally, the EIS studies showed higher value of $\mathrm{R}_{\mathrm{f}}$ for quaternary Ni-Fe-P-C coating than both ternary $\mathrm{Ni}-\mathrm{P}-\mathrm{C}$ and $\mathrm{Ni}-\mathrm{Fe}-\mathrm{C}$ coatings by factor of $78 \%$ and $16 \%$, respectively. These results revealed that the quaternary coating of $\mathrm{Ni}-\mathrm{Fe}-\mathrm{P}-\mathrm{C}$ is a more active 
electrocatalyst than both $\mathrm{Ni}-\mathrm{P}-\mathrm{C}$ and $\mathrm{Ni}-\mathrm{Fe}-\mathrm{C}$ in alkaline solution and could be used as a high active and inexpensive electrocatalyst for the HER.

Table 4. Kinetic parameters of the HER obtained on studied coatings from the steadystate polarization curves and EIS measurements in $1 \mathrm{M} \mathrm{NaOH}$ using NLS program.

\begin{tabular}{lccccccc}
\hline Coating & $\mathrm{k}_{1}\left(\mathrm{~mol} \mathrm{~cm}^{-2} \mathrm{~s}^{-1}\right)$ & $\begin{array}{c}\mathrm{k}_{2} \\
\left(\mathrm{~mol} \mathrm{~cm}^{-2} \mathrm{~s}^{-1}\right)\end{array}$ & $\begin{array}{c}\mathrm{k}_{\mathrm{av}} \\
\left(\mathrm{mol} \mathrm{cm}^{-2} \mathrm{~s}^{-1}\right)\end{array}$ & $\begin{array}{c}\mathrm{k}_{\mathrm{intr}}=\mathrm{k}_{\mathrm{av}} / \mathrm{R}_{\mathrm{f}} \\
\left(\mathrm{mol} \mathrm{cm}^{-2} \mathrm{~s}^{-1}\right)\end{array}$ & $\begin{array}{c}\mathrm{j}_{0} / \mathrm{R}_{\mathrm{f}} \\
\left(\mathrm{A} \mathrm{cm}^{-2}\right)\end{array}$ & $\beta_{1}$ & $\beta_{2}$ \\
\hline Ni-P-C & $(9.0 \pm 0.3) \times 10^{-8}$ & $(5.5 \pm 0.1) \times 10^{-9}$ & $(5.2 \pm 0.3) \times 10^{-9}$ & $(2.2 \pm 0.3) \times 10^{-11}$ & $5.1 \times 10^{-5}$ & 0.55 & 0.58 \\
Ni-Fe-C & $(1.5 \pm 0.5) \times 10^{-8}$ & $(6.5 \pm 1.3) \times 10^{-9}$ & $(4.5 \pm 0.8) \times 10^{-9}$ & $(1.1 \pm 0.5) \times 10^{-12}$ & $5.8 \times 10^{-6}$ & 0.62 & 0.50 \\
Ni-Fe-P-C & $(9.5 \pm 0.3) \times 10^{-7}$ & $(9.2 \pm 1.0) \times 10^{-8}$ & $(8.4 \pm 0.9) \times 10^{-8}$ & $(2.9 \pm 0.3) \times 10^{-11}$ & $6.6 \times 10^{-6}$ & 0.61 & 0.63 \\
\hline
\end{tabular}

\section{Stability of Ni-Fe-P-C electrode}

The electrochemical stability of the electrode material is one of the important characteristics that must be established. Thus, the Ni-Fe-P-C coating was tested through long term working experiments by operating at a constant applied overpotential, $\eta=-130 \mathrm{mV}$, at $298 \mathrm{~K}$ in $1 \mathrm{M} \mathrm{NaOH}$, and its current response (chronoamperogram) was recorded (Fig. 7). Between consecutive measurements, with an interval of about 20 days, the coating was kept in $1 \mathrm{M} \mathrm{NaOH}$ at $298 \mathrm{~K}$. The corresponding current monitored during this time on the electrode, demonstrated no significant changes. This behavior showed that the quaternary coating of Ni-Fe-P-C was electrochemically stable for a relatively long time (104 days) for the HER in alkaline solutions.

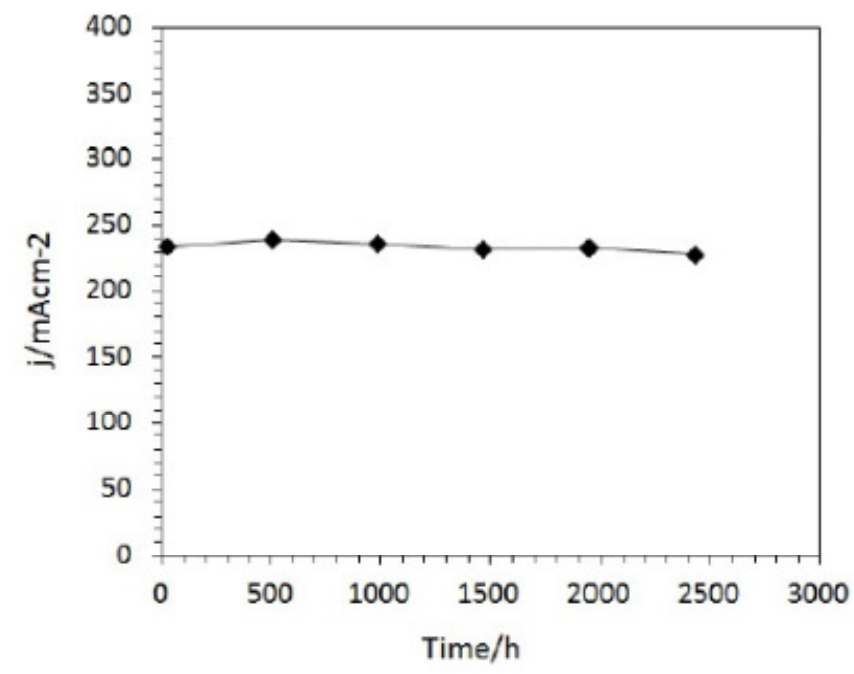

Figure 7. Variation of the quaternary Ni-Fe-P-C composite coating response, observed current densities at a constant applied overpotential $(\eta=-130 \mathrm{mV})$ vs. time obtained in $1 \mathrm{M} \mathrm{NaOH}$ at $298 \mathrm{~K}$.

\section{Conclusions}

The quaternary coating of Ni-Fe-P-C was prepared at low current densities by electrodeposition method from an aqueous solution and studied toward the HER, for the first time. Quantitative kinetic information obtained by the Tafel and EIS 
measurements revealed that $\mathrm{Ni}-\mathrm{Fe}-\mathrm{P}-\mathrm{C}$ coatings have considerably higher electrocatalytic activity for the HER than the previously studied ternary coatings of $\mathrm{Ni}-\mathrm{P}-\mathrm{C}$ and $\mathrm{Ni}-\mathrm{Fe}-\mathrm{C}$ in $1 \mathrm{M} \mathrm{NaOH}$ solution. The average apparent rate constants of the assumed mechanism, Volmer-Heyrovský, were estimated by simultaneous approximation of the Tafel and EIS data. The $\mathrm{k}_{2}$ values were smaller than those obtained for hydrogen adsorption rate constants $\left(\mathrm{k}_{1}\right)$ for Ni-Fe$\mathrm{P}-\mathrm{C}$ electrode. This behavior revealed that Heyrovsky reaction is the ratedetermining step for the HER kinetics on this electrode. Its activity is originated from high surface area and from the intrinsic properties of the coating. Also, the $\mathrm{Ni}-\mathrm{Fe}-\mathrm{P}-\mathrm{C}$ electrode was physically, chemically, and electrochemically stable for a relatively long time and showed high electrocatalytic activity for the HER.

\section{Acknowledgments}

The authors thank to Department of Applied Chemistry (Malek-Ashtar University of Technology, Isfahan, Iran) for financially support and providing the lab facilities to bring about this work.

\section{References}

1. Veziroglu TN, Barbir F. Hydrogen-the wonder fuel. Int J Hydrogen Energ. 1992;17:391-404.

2. Kim HK, Yang DC, Jang IS, et al. Effects of pretreatment of LM$\mathrm{Ni}_{3.9} \mathrm{Co}_{0.6} \mathrm{Mn}_{0.3} \mathrm{Al}_{0.2}$ alloy powders in a $\mathrm{KOH} / \mathrm{NaBH}_{4}$ solution on the electrode characteristics and inner pressure of nickel-metal-hydride secondary batteries. Int J Hydrogen Energ. 2009;34:9570-9575.

3. Zeng $\mathrm{K}$, Zhang $\mathrm{D}$. Recent progress in alkaline water electrolysis for hydrogen production and applications. Prog Energ Combust. 2010;36:307326.

4. Losiewicz B, Budniok A, Rowinski E, et al. The structure, morphology and electrochemical impedance study of the hydrogen evolution reaction on the modified nickel electrodes. Int J Hydrogen Energ. 2004;29:145-157.

5. Safizadeh F, Gali E, Houlachi G. Electrocatalysis developments for hydrogen evolution reaction in alkaline solutions- A Review. Int $\mathrm{J}$ Hydrogen Energ. 2015;40:256-274.

6. Shan Z, Liu Y, Chen Z, et al. Amorphous Ni-S-Mn alloy as hydrogen evolution reaction cathode in alkaline medium. Int $\mathbf{J}$ Hydrogen Energ. 2008;33:28-33.

7. Lasia A. In: Vielstich W, Lamm A, Gasteiger HA. editors. Handbook of fuel cells; fundamentals, technology and applications. Part 4. Hydrogen evolution reaction. Vol. 2. Wiley; 2003. p 416.

8. Pierozynski B, Mikolajczyk T, Turemko M, et al. Hydrogen evolution reaction at Pd-modified carbon fibre in $0.1 \mathrm{M} \mathrm{NaOH}$. Int J Hydrogen Energ. 2015;40:1795-1799. 
9. Du H, Gu S, Liu R, et al. Highly active and inexpensive iron phosphide nanorods electrocatalyst towards hydrogen evolution reaction. Int $\mathbf{J}$ Hydrogen Energ. 2015. In Press.

10. Kichigin VI, Shein AB. Kinetics and mechanism of hydrogen evolution reaction on cobalt silicides in alkaline solutions. Electrochim Acta. 2015;164:260-266.

11. Shervedani RK, Madram AR. Kinetics of hydrogen evolution reaction on nanocrystalline electrodeposited $\mathrm{Ni}_{62} \mathrm{Fe}_{35} \mathrm{C}_{3}$ cathode in alkaline solution by electrochemical impedance spectroscopy. Electrochim Acta. 2007;53:426433.

12. Shervedani RK, Madram AR. Electrocatalytic activities of nanocomposite $\mathrm{Ni}_{81} \mathrm{P}_{16} \mathrm{C}_{3}$ electrode for hydrogen evolution reaction in alkaline solution by electrochemical impedance spectroscopy. Int $\mathrm{J}$ Hydrogen Energ. 2008;33:2468-2476.

13. Hitz C, Lasia A. Determination of the kinetics of the hydrogen evolution reaction by the galvanostatic step technique. $\mathrm{J}$ Electroanal Chem. 2002;532:133-140.

14. Kubisztal J, Budniok A, Lasia A. Study of the hydrogen evolution reaction on nickel-based composite coatings containing molybdenum powder. Int $\mathbf{J}$ Hydrogen Energ. 2007;32:1211-1218.

15. Inzelt G., Lang G., Model dependence and reliability of the electrochemical quantities derived from the measured impedance spectra of polymer modified electrodes. J. Electroanal. Chem. 378 (1994) 39-49.

16. Brug GJ, van der Eden ALG, Rehbach MS, et al. The analysis of electrode impedances complicated by the presence of a constant phase element. J Electroanal Chem. 1984;176:275-295.

17. Milica PMK, Vladimir MN, Gvozden ST, et al. Electrocatalytic activation of $\mathrm{Ni}$ electrode for hydrogen production by electrodeposition of $\mathrm{Co}$ and $\mathrm{V}$ species. Int J Hydrogen Energ. 2009;34:703-709.

18. Trasatti S. In: Gerischer H, Tobias CW, editors. Advances in electrochemical science and engineering. Vol 2. Weinheim. VCH; 1992. p 2.

19. Harrington DA, Conway BE. Kinetic theory of the open-circuit potential decay method for evaluation of behavior of adsorbed intermediates: Analysis for the case of the $\mathrm{H}_{2}$ evolution reaction. J Electroanal Chem. 1987;221:1-21. 